\title{
Experimental Determination of Bubble Size in Solution of Surfactants of the Bubble Column
}

\author{
Maedeh Asari ${ }^{1}$ and Faramarz Hormozi ${ }^{2 *}$ \\ ${ }^{1}$ Faculty of Engineering- Department of Chemical Engineering, Islamic Azad University, Shahrood Branch, Shahrood, Iran \\ ${ }^{2}$ Faculty of Chemical, Gas and Petroleum Engineering, Semnan University, Semnan, Iran
}

\begin{abstract}
This paper focuses on the effect of surfactants on the bubble size. Bubble size in Sodium dodecyl sulfate / water system were investigated at various superficial gas velocities $(0.13,0.26$ and $0.5 \mathrm{~cm} / \mathrm{s})$. On the other hands, Bubble diameter was determined for different values of Sodium dodecyl sulfate surfactant concentration. Surfactant concentration in water were $0.05,0.02$ and 0.1 vol.\%. Tap water and aqueous solutions with surfactants (anionic, non-ionic and zwitterionic) are used as liquid phases. The bubbles size in this phase is determined at $\mathrm{C}=0.05 \%$ vol and $u_{g}=0.13 \mathrm{~cm} / \mathrm{s}$. The bubbles are generated into a small-scale bubble column making of Plexiglas with height of 1.2 $\mathrm{m}$. High speed photography techniques are used to measure the bubble size. The experimental results were shown that bubble diameter in Sodium dodecyl sulfate /water system is larger than other systems. In solution of Sodium dodecyl sulfate, Sauter mean bubble diameter (Location A and D) decreases when superficial gas velocity increased.
\end{abstract}

Keywords: Bubble column; Surfactant; Bubble size

\section{Introduction}

Bubble column reactors are widely used in chemical and biochemical processes such as oxidation, chlorination, polymerization, hydrogenation, synthetic fuels by gas conversion processes, fermentation and wastewater treatment. Bubble columns can be employed in many mass transfer processes [1]. However, the lack of a more complete knowledge on the bubble column fluid dynamic behavior in its various regimes causes several operational difficulties and design uncertainties, which include poor predictions of the mean bubble diameter, gas hold up and interfacial area [2,3]. A bubble column reactor is basically a cylindrical vessel with a gas distributor at the bottom [4]. The interfacial area available for mass transfer is the most important design parameter defined by gas holdup and bubble size which in turn are affected by the operating conditions, the physicchemical properties of the two phases, the gas sparger type and the column geometry [5]. Bubble column are preferred to be two-phase contactors for their ease of operation, maintenance and absence of moving parts, yet they have complex hydrodynamics characteristics [6]. Knut [7] studied dynamic simulation of 2D bubble column and shown that two dimensional dynamic simulation of the flat bubble column is feasible, applying state-of the art dynamic turbulence models. Surfactant designates a substance that exhibits some superficial or interfacial activity. Different methods have been employed for bubble dimension evaluation [8]. Gas bubbles in transparent fluids can be photographed and measured, usually using image-analysis [9]. This is the simplest technique but cannot be used with opaque media such as those found in fermentation systems. Statistical models [10] are required to calculate bubble-size distributions from the measured chord lengths. Several authors studied bubble size and interfacial phenomena in different types of bubble column reactors. Colella et al. [11] studied the interfacial mechanisms focusing on the coalescence and breakage phenomena of bubbles in three different bubble columns. They investigated the influences of gas superficial velocity and different hydrodynamic configurations on bubble size distribution in the bubble columns. Lehr and Mewes [12] evaluated the bubble sizes in two-phase flows. They predicted the bubble size distribution in bubble columns including the formation of large bubbles at high superficial gas velocities. Schäfer et al. [13] discussed the influence of operating conditions and physical properties of gas and liquid phase on initial and stable bubble sizes in a bubble column reactor under industrial conditions. Akita and Yoshida [14] determined the bubble size distribution using a photographic technique. The gas was sparged through perforated plates and single-orifice using various liquids (water, aqueous and pure glycol, methanol, and carbon tetrachloride). It has been reported in the literature that with increase in surfactant concentration, coalescence time increases [15]. Sardeing et al. [16] reported that in superficial gas velocities between $1.5 \times 10^{-4}-2 \times 10^{-4} \mathrm{~m} / \mathrm{s}$, bubble diameter was in surfactant solutions between $1 \mathrm{~mm}-8 \mathrm{~mm}$. In these studies we have also analysed the influence of SDS surfactant concentration and the gas flow-rate upon the bubble diameter in bubble column. On the other hand, the bubble size distribution has been studied in ionic, nonionic and zwitterionic surfactants on the bubble column. Yang and Maa [17] studied ionic surfactants (SDS, SDBS) in water systems and showed that the coalescence time increased with increasing surfactant concentration.

\section{Experimental Setup and Technique}

The schematic diagram of the modified bubble column is shown in Figure 1. It consists of an air compressor, (1), a rotameter, (2), an halegon lamp, (3), etc. Four different surfactant (Tween20, [CAS No:9005-64-5], Triton X-100, [CAS No:9002-93-1], Cocamidopropy Betaine, [CAS No:61789-40-0], SDS(Sodium dodecyl sulfate), [CAS No:151-21-3]) have been used in the present work. All of surfactants were purchased from Merck Company (Germany). Bubble size is reported at ambient conditions [atmospheric pressure $25( \pm 0.5)^{\circ} \mathrm{C}$ ]. The gas from the compressed air line passed through calibrated rotameter. The photographic method, used in this study to determine

*Corresponding author: Faramarz Hormozi, Faculty of Chemical, Gas and Petroleum Engineering, Semnan University, Semnan, Iran, Tel: +98 2313355120 ; Fax : +98 231 3366911; E-mail: fhormozi@semnan.ac.ir

Received January 08, 2014; Accepted January 22, 2014; Published January 29 2014

Citation: Asari M, Hormozi F (2014) Experimental Determination of Bubble Size in Solution of Surfactants of the Bubble Column. J Adv Chem Eng 1: 101. doi: 10.4172/2090-4568.1000101

Copyright: (c) 2014 Asari M, et al. This is an open-access article distributed under the terms of the Creative Commons Attribution License, which permits unrestricted use, distribution, and reproduction in any medium, provided the original author and source are credited. 
the bubble size of the two-phase mixture, has been developed using a rectangular bubble column $(20 \mathrm{~cm} \times 5 \mathrm{~cm} \times 120 \mathrm{~cm})$. The liquid column heights during the operation were $45 \mathrm{~cm}$. To determine profiles of ellipsoid, bubble was monitored over distance ca. $1 \mathrm{~m}$ and was using professional video recorder. The photographs were taken by a digital camera (Casio Exilim (EX-F1)) taken along the height of the column, from bottom to top. The digital photographs were processed and enhanced by using Image Processing MATLAB Software that enabled to distinguish clearly the bubble boundaries. The diameters of the bubbles were determined from photographs of the operating column, 5, 20, 30 and $40 \mathrm{~cm}$ above the gas distributor. The images were taken at three axial positions for different operating conditions. The $2 \mathrm{~d}$ picture shapes of the bubbles were approximated by ellipsoid whose maximum and minimum axes were automatically computed by the software program used for image analysis $[18,19]$. The third dimension was calculated with the assumption that the bubbles are symmetric around the minimum axes. From the known values of maximum and minimum axes, an equivalent ellipsoid bubble diameter was calculated by the following equation [20]:

$$
\mathrm{d}_{\mathrm{be}}=\left(d_{\mathrm{b}, \max }^{2} d_{\mathrm{b}, \min }\right)^{1 / 3}
$$

where $d_{b, \max }$ and $d_{b, \min }$ are the ellipsoid maximum and minimum axes of bubble. The distributions were obtained by sorting the equivalent diameters of bubbles into different uniform classes. At a particular operating condition, the bubble picture taken from different locations of the column are shown in Figure 2. The Sauter mean bubble diameter $\left(d_{32}\right)$ is defined as the volume-to-surface mean bubble diameter [21]:

$$
d_{32}=\frac{\sum_{i=1}^{N} n_{i} d_{B i^{3}}}{\sum_{i=1}^{N} n_{i} d_{B i^{2}}}
$$

where $n_{i}$ is the number of bubbles of diameter $d_{B i}$.

Between 1000 and 3000 bubbles were counted for determination of the size distribution, using 30 photographs.

\section{Bubble Size Distribution}

Bubble coalescence and breakup play a significant role in determining bubble size distribution. Coalescence was found to take place when more than about a half of the projected area of the following bubble was overlapped with that of the leading bubble at the critical distance. In contrast, the breakup occurred in the case the overlapping

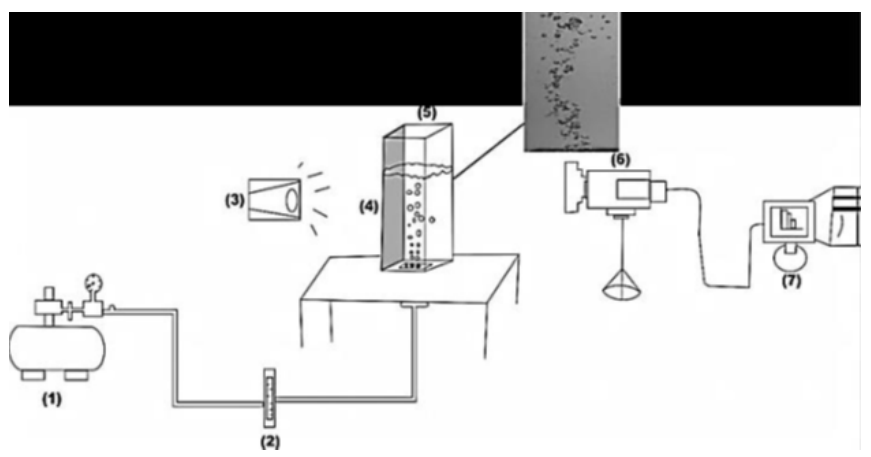

Figure 1: Gas-liquid experimental set-up. (1): Air compressor (2): Rotameter (3): Halogen lamp (4): Plexiglas plate (5): Bubble column (6): Camera (7): Image processing.

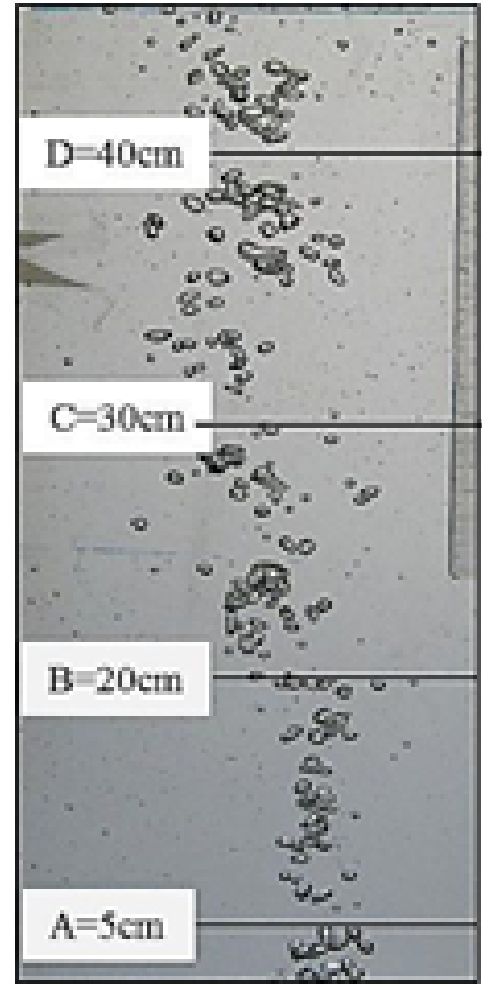

Figure 2: Photograph taken from different location of column in Tween20/ water system at $C_{s}=0.05 \%$ vol and $u_{g}=0.13 \mathrm{~cm} / \mathrm{s}$ Location A, B, C and D.

was less than about a half of the projected area of the following bubble. Thus, when the leading bubble is larger than the following one, the latter has a tendency to coalesce. In contrast, in the case of the smaller size of the leading bubble, the following bubble tends to breakup. Coalescence is significantly influenced by the physical properties of the liquid. Analysis of bubble size in bubble columns must distinguish between bubble-size distribution just after bubble formation at the sparger and size distribution further away from the distributor [18]. Two basic methods - photography and probe techniques - exist for determining bubble size, however; they do not lead to identical results. Both methods are subject to certain limitations in view of the marked bubble selection that may occur (i.e., not all bubble sizes can be detected). In particular, any measurement method only leads to realistic results if the flow is homogeneous (i.e., a narrow bubble-size distribution is found). As yet, no method can be recommended for the measurement of large bubbles in the heterogeneous flow regime.

\section{Results and Discussion}

\section{Effect of superficial gas velocity upon bubble size in SDS +water system}

First, there is general observation that applies to all solutions. For example, regardless of type and presence of chemical added, the average bubble radius decreases with increasing of gas flow rate. Figure 3 show bubble size distribution for SDS-water system in regions A and D. As the gas flow rate increases the gas holdup and kinetic energy increases which increase turbulent intensity, bubble- bubble interactions, velocity of bubbles and the probability of coalescence which is because of as increasing collision frequency between bubbles with increase in gas flow rate (Figure 3). 


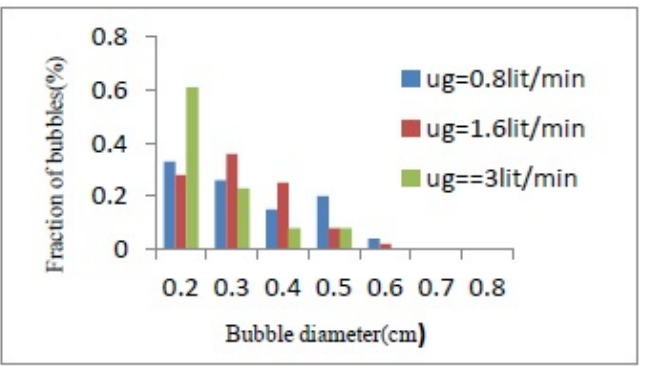

(a)

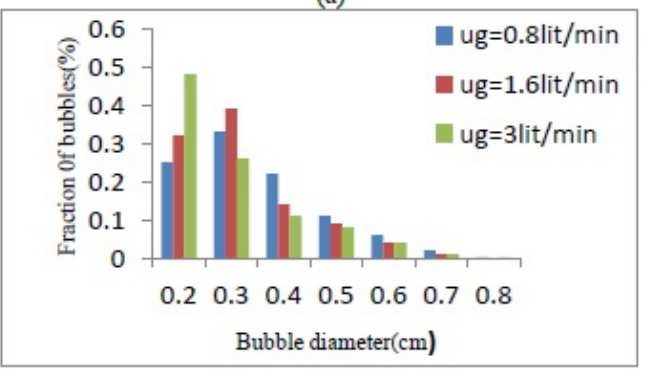

(b)

Figure 3: Effect of gas flow rate upon bubble size in SDS/water system at $C_{s}=0.02 \%$ vol. (a) Location A; (b) Location D.

The probability of coalescence is higher in region $\mathrm{D}$ but the bubble size decreases with increasing superficial gas velocity in $\mathrm{A}$ and $\mathrm{D}$ location. This is due to bubble break- up with increasing gas flow rate. Also as the superficial gas velocity increases, the Sauter mean bubble diameter decreases (Figure 4). For $u_{g}$ greater than $0.13 \mathrm{~cm} / \mathrm{s}$ smallest bubbles are obtained in solution of lowest static surface tension. The rate of coalescence decreases with the gas flow rate increasing (Figure 4).

\section{Effect of SDS concentration upon bubble size}

One of the parameters that effect bubble size, is surfactant concentration. Effect of various SDS concentrations (0.02, 0.05 and $0.1 \% \mathrm{vol})$ at $u_{g}=0.13 \mathrm{~cm} / \mathrm{s}$ on bubbles diameter is shown in Figure 5 . SDS addition to pour water decreased the bubbles diameter. Further, surfactant concentration enhancement decreased the of bubbles diameters by decreasing the surface tension and buoyancy force. Sardeing et al. [16] used various surfactants and investigated that bubbles diameter decreased about $30 \%$ (as an average value). The bubble size distribution in an emulsification processes is a result of the competition between opposite processes, bubble breakage and bubblebubble coalescence. It was shown experimentally that the bubble size rapidly decreases with an increase of SDS concentration [22]. Sample photographs of the bubble populations shown in Figure 6. They clearly showed that as the SDS concentration increases, the bubble populations will become smaller in size. Sauter mean bubble diameter $\left(d_{v s}\right)$ decreases due to SDS concentration increasing (Figure 7).

\section{Effect of ionic, non-ionic and zwitterionic surfactants on} bubble size

Presence of surfactants has a great effect on the bubble diameters. The bubble size distribution was obtained in four axial locations A (of height $0.05 \mathrm{~m}$ ), B (of height $0.2 \mathrm{~m}$ ), C (of height $0.3 \mathrm{~m}$ ) and D (of height $0.4 \mathrm{~m}$ ) from the bottom of the column (Figure 2). Typical results

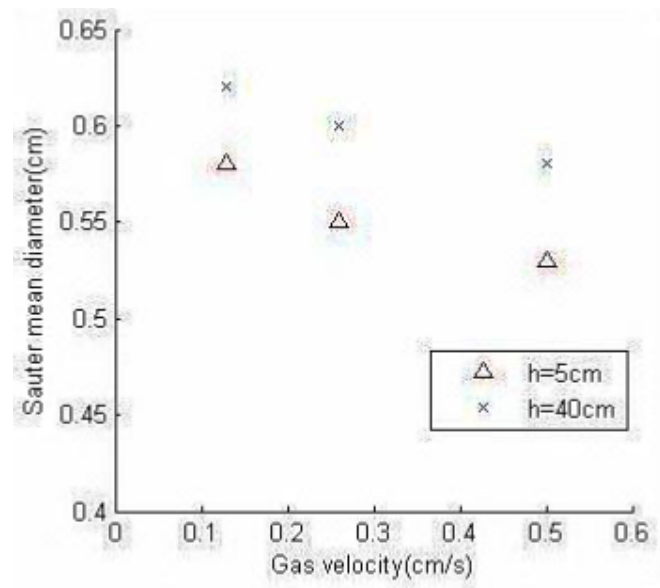

Figure 4: Influence of gas flow rate upon Sauter mean bubble diameter in SDS/water system at $C_{s}=0.02 \%$ vol.

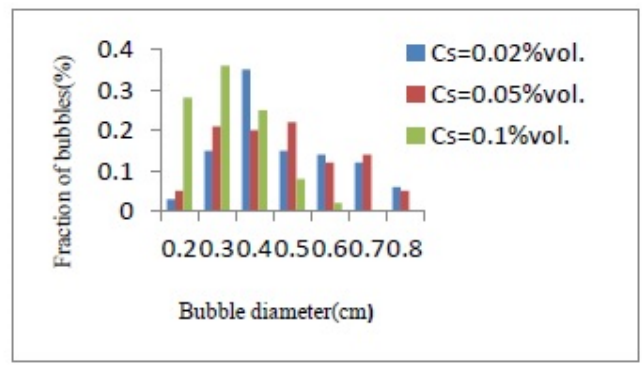

(a)

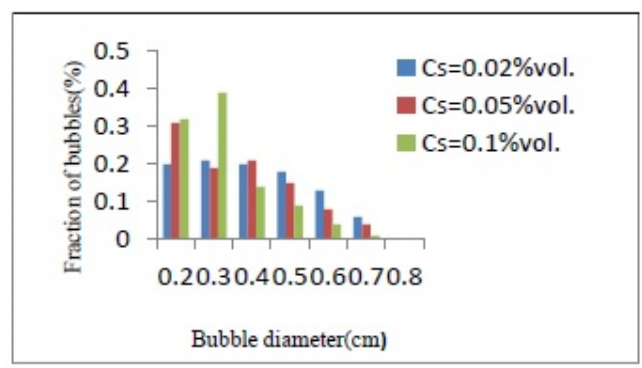

(b)

Figure 5: Influence of SDS concentration upon bubble diameter at $u_{g}=0.13 \mathrm{~cm} / \mathrm{s}$; (a) Location A. (b) Location D.

for these four locations are presented in Figure 8. It is seen that the bubble size in location D are greater than location A, B and C (Figure 2). The average bubble size in location $C$ and $B$ are almost the same. All calculations regarding goodness of fit have been performed by MATLAB software. Bubble diameter increased with increasing the distance from the bottom of the column due to the coalescence of smaller bubbles. The coalescence bubbles of location A go up due to their buoyancy and accumulate in location B, C and D. Also the bubble number flux varies in different locations due to the same reason. That bubble number flux decreases in location $\mathrm{C}$ and $\mathrm{D}$ over location $\mathrm{A}$ and $\mathrm{B}$ is result of an increase in bubble size due to coalescence. As shown in Figure 8, there is no significant variation of bubble size in location 


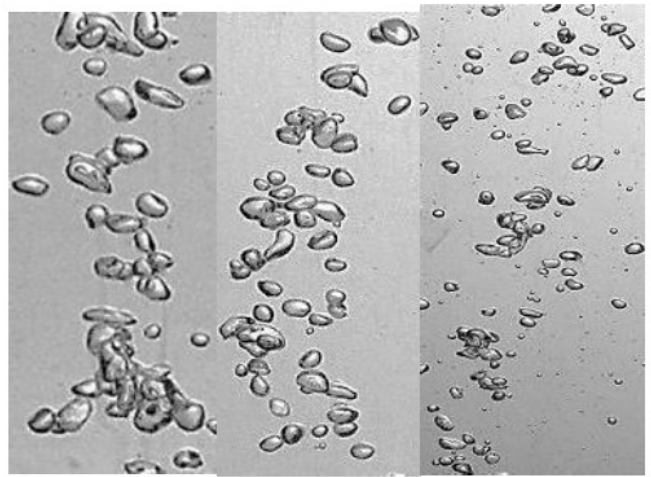

(a)

(b)

(c)

Figure 6: Example of photograph of bubbles at $u=0.13 \mathrm{~cm} / \mathrm{s}$ for SDS/water system; (a) $C_{s}=0.02 \%$ vol; (b) $C_{s}=0.05 \%$ vol; (c) $C_{s}=0.1 \%$ vol.

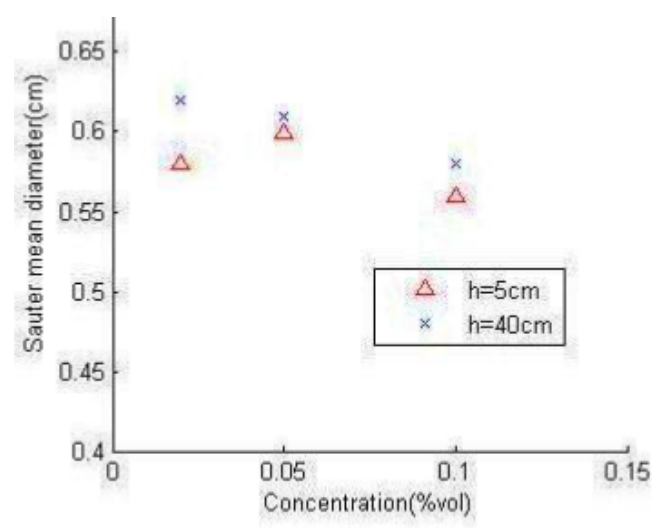

Figure 7: Effect of SDS concentration upon sauter mean diameter at ug=0.13 $\mathrm{cm} / \mathrm{s}$.

$\mathrm{B}$ and $\mathrm{C}$. The bubble size in location $\mathrm{A}$ is much smaller than other locations due to a break-up.

Figure 8 shows the relation between the detached bubble diameter and fraction of bubbles for the different surfactants. Whatever the liquid properties are, the bubble diameters vary between 0.2 and 0.8 for $\mathrm{ug}=0.13 \mathrm{~cm} / \mathrm{s}(\mathrm{d}<0.2 \mathrm{~cm}$, effective force is surface tension and bubbles are spherical). For this gas flow rate, the order below is observed:

$$
d_{\text {SDS }}>d_{\text {Betaine }}>d_{\text {Triton X-100 }}>d_{\text {Tween20 }}
$$

Sauter mean bubble diameter was investigated in four different axial positions (A, B, C and D).Typical profile of $d_{32}$ as a function of height above sparger are show in Figure 9. The sauter mean bubble diameter varies with axial location due to coalescence effect whereas the variation of gas holdup is due to variation of bubble number flux. The values of $d_{32}$ obtained in the range of 0.4-0.65. Increasing in height increases $d_{32}$ at all type of surfactants. The value of $d_{32}$ in SDS+water system is more than other systems.

\section{Conclusion}

Effect of surfactant on the bubble size in rectangular bubble column has been studied. In order to obtain bubble size distribution about 1000-3000 bubbles were analyzed. The evaluation of bubble size distribution in different location of the column and the influence gas (a)

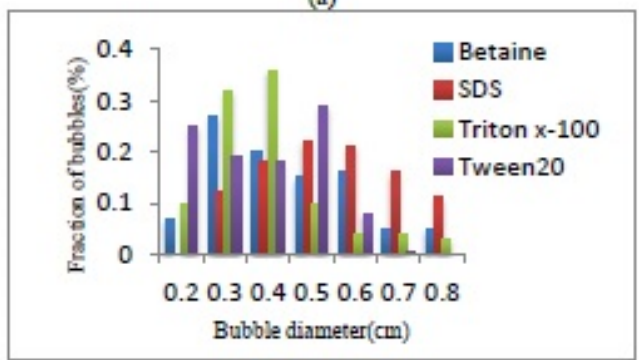

(b)

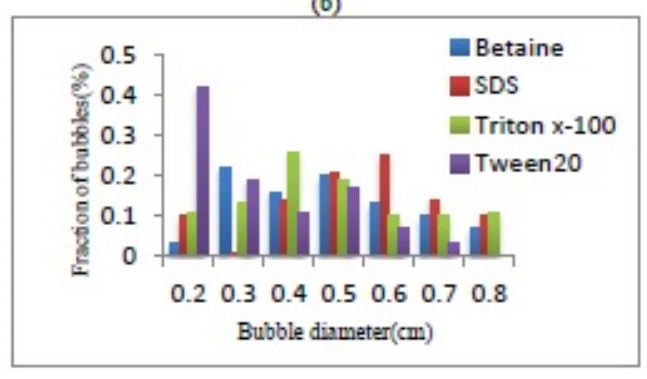

(c)

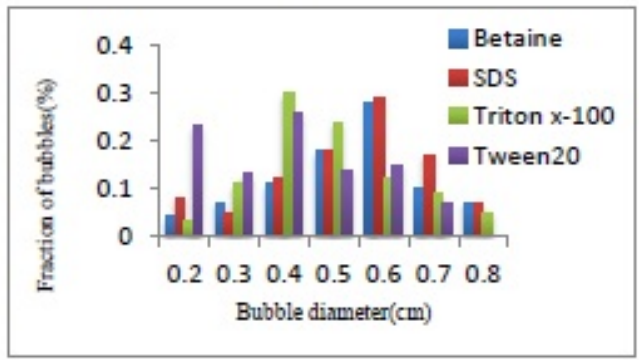

(d)

Figure 8: Bubble size distribution for solution surfactant with water location of (a) $\mathrm{h}=5 \mathrm{~cm}$; (b) $\mathrm{h}=20 \mathrm{~cm}$; (c) $\mathrm{h}=30 \mathrm{~cm}$; (d) $\mathrm{h}=40 \mathrm{~cm}$ at $C_{s}=0.05 \% \mathrm{vol}$ and $u_{g}=0.013 \mathrm{~cm} / \mathrm{s} . \mathrm{a}$

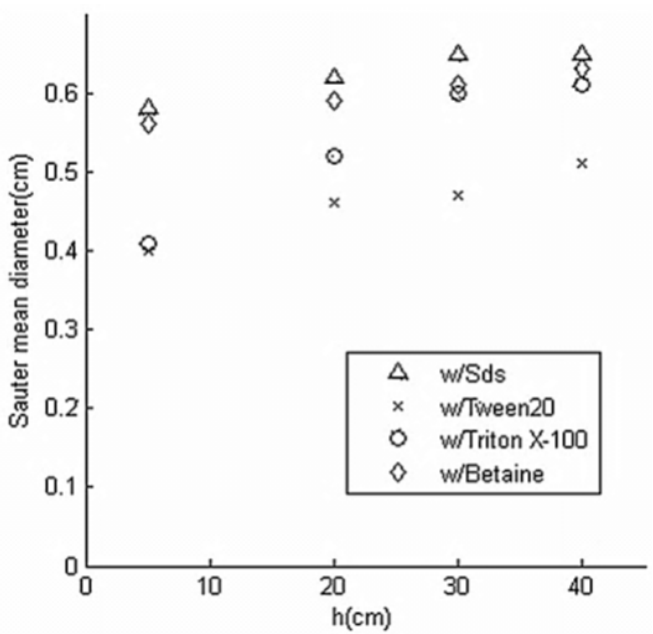

Figure 9: Sauter mean bubble diameter as a function of distance from gas sparger. 
flow rate and SDS concentration were pointed out. The measurements were done using photographic techniques. The bubble size in bubble column increased with increasing distance from the bottom of the column due to coalescence. The bubble diameter in SDS+ water system were bigger than other systems (Betaine, Triton X-100 and Tween 20 at $C_{s}=0.05 \%$ vol and $u_{g}=0.013 \mathrm{~cm} / \mathrm{s}$ ). When gas flow rate increase (SDS +water system), an increase in the number of small bubbles was also observed, and Sauter mean bubble diameter also decreased due to breakage bubbles. The Sauter mean bubble diameter decreases, when SDS concentration increasing.

\section{Nomenclature}

$d_{b, \max }$ major axis of the projected ellipsoid(m)

$d_{b, \min }$ minor axis of the projected ellipsoid(m)

$d_{32} \quad$ sautor mean diameter bubble $(\mathrm{m})$

ug superficial gas velocity $(\mathrm{m} / \mathrm{s})$

$h \quad$ distance from gas distributor $(\mathrm{m})$

d diameter $(\mathrm{m})$

$C_{s}$ surfactant concentration

\section{References}

1. Ariyapadi S, Balachandar R, Berruti $F$ (2004) Effect of surfactant on the characteristics of a droplet-laden jet. Chemical Engineering and Processing: Process Intensification 43: 547-553.

2. Al-Masry WA, Ali EM, Aqeel YM (2005) Determination of bubble characteristics in bubble columns using statistical analysis of acoustic sound measurements. Chemical Engineering Research and Design 83: 1196-1207.

3. Lage PLC, Esposito RO (1999) Experimental determination of bubble size distributions in bubble columns: prediction of mean bubble diameter and gas hold up. Powder Technology 101: 142-150.

4. Kantarci N, Borak F, Ulgen KO (2005) Review Bubble column reactors. Process Biochemistry 40: 2263-2283.

5. Camarasa E, Vial C, Poncin S, Wild G., Midoux N, et al. (1999) Influence of coalescence behaviour of the liquid and of gas sparging on hydrodynamics and bubble characteristics in a bubble column. Chemical Engineering and Processing: Process Intensification 38: 329-344.

6. Waheed AAM, Emad MA, Yehya MA (2006) Effect of antifoam agent on bubble characteristic in bubble columns based on acoustic sound measurements. Chemical Engineering Science 61: 3610-3622.
7. Knut B (2005) Dynamic simulation of a 2Dbubble column. Chemical Engineering Science 60: 5294-5304.

8. Gómez-Díaz D, Navaza JM, Sanjurjo B (2008) Interfacial area evaluation in a bubble column in the presence of a surface-active substance Comparison of methods. Chemical Engineering Journal 144: 379-385.

9. Machon V, Pacek AW, Nienow AW (1997) Bubble size in electrolyte and alcoho solutions in a turbulent stirred vessel. Chemical Engineering Science 75: 339 348 .

10. Clark NN, Turton R (1998) C Chord length distributions related to bubble size distributions in multiphase flows. International Journal multiphase Flow 14: 413-424.

11. Colella D, Vinci R, Bagatin M, Masi E, Abu Bakr (1999) A study on coalescence and breakage in three different bubble columns. Chemical Engineering Science 54: 4767-4777.

12. Lehr F, Mewes D (2001) A transport equation for the interfacial area density applied to bubble columns. Chemical Engineering Science 56: 1159-1166.

13. Schäfer R, Merten C, Eigenberger G (2002) Bubble size distribution in a bubble column reactor under industrial conditions. Experimental Thermal and Fluid Science 26: 595-604.

14. Akita K, Yoshida F (1974) Bubble size, interfacial area and liquid-phase mass transfer coefficient in bubble columns. Ind. Eng. Chem. Process Des Dev 13 84-91.

15. Ghosh P, Juvekar VA (2002) Analysis of the drop rest phenomenon. Chemical Engineering Research and Design 80: 715-728.

16. Sardeing R, Painmanakul P, Hébrard G (2006) Effect of surfactants on loquidside mass transfer coefficient in gas-liquid systems: A first step to modeling. Chemical Engineering Science 61: 6249-6260.

17. Yang YM, Maa JR (1984) Bubble coalescence in dilute surfactant solution Journal of Colloid and Interface Sci 98: 120-125.

18. Majumder SK, Kundu G, Mukherjee D (2006) Bubble size distribution and gas-liquid interfacial area in a modified downflow bubble column. Chemical Engineering Journal 122: 1-10.

19. Polli M, Stanislao MD, Bagatin R, Abu Bakr E, Masi M (2002) Bubble size distribution in the sparger region of bubble columns. Chemical Engineering Science 57: 197-205.

20. Couvert A, Roustan M, Chatellier P (1999) Two-phase hydrodynamic study of a rectangular airlift loop reactor with an internal baffle. Chemical Engineering Science 54: 5245-5252.

21. Asgharpour M, Mehrnia MR, Mostoufi N (2011) Effect of surface contaminants on oxygen transfer in bubble column reactors. Biochemical Engineering Journal 49: 351-360.

22. García-Abuín A, Gómez-Díaz D, Losada M, Navaza JM (2012) Bubble column gas-loquid interfacial area in a polymer + surfactant + water system. Chemical Engineering Science 75: 334-341. 